\title{
A ÉTICA - COMO MOTOR DA INOVAÇÃO EMPRESARIAL E DA SUSTENTABILIDADE ORGANIZACIONAL
}

\author{
Clotilde Passos ${ }^{1}$
}

\begin{abstract}
Resumo: A ética tem vindo de forma crescente a ganhar importância e espaço nas organizações e a inovação assume-se cada vez mais como um fator chave da sustentabilidade empresarial. Várias abordagens teóricas, desenvolvidas nos últimos anos, sustentam os inegáveis benefícios, económicos, ambientais, humanos $e$ sociais da ética empresarial. Outras, afirmam que as empresas geram e conservam as suas vantagens competitivas primordialmente através da inovação. Neste contexto, o objetivo deste artigo é propor um modelo conceptual que permita perceber a relação existente entre os dois conceitos e, analisar, em que medida a implementação da gestão ética nas empresas promove a inovação e a sustentabilidade organizacional. A crescente importância da ética e da inovação nas organizações e a necessidade de novos modelos de gestão na economia moderna, justificam o interesse do estudo.
\end{abstract}

Palavras chave: Ética, Inovação empresarial e sustentabilidade organizacional

\begin{abstract}
Ethics importance has been growing in organizations, and innovation is seen ever more as a key factor in enterprise sustainability. Several theoretical approaches developed in recent years support the undeniable economic, social and human benefits of enterprise ethics. Other approaches sustain that enterprises create and retain their competitive advantages mostly through innovation. On this context, the goal of this article is to propose a conceptual model which allows understanding of the existing relationship between these two concepts, analyzing how the implementation of ethical management in enterprises promotes organizational sustainability and innovation. The growing importance of ethics and innovation in organizations and the need for new management models in modern economy are the reasons for this study.
\end{abstract}

Keywords: Ethics, entrepreneurial innovation and organizational sustainability.

\footnotetext{
${ }^{1}$ Doutorada em Gestão. Professora do Centro Regional de Viseu da Universidade Católica Portuguesa. E-mail: clotilde.passos@gmail.com
} 


\section{INTRODUÇÃO}

A ética sempre esteve presente na história como resposta aos problemas básicos apresentados pelas relações entre os homens e em particular, pelo seu comportamento moral efetivo (Aguilar, 1996). De facto, como refere Almeida (2007:31) a presença de preocupações éticas na gestão de empresas e de negócios pode ser encontrada em inúmeros textos e exemplos relatados ao longo da história, no entanto, durante as últimas décadas este tema tornou-se alvo de uma atenção sem precedentes. A preocupação com as questões éticas nos negócios tem aumentado ao longo das últimas duas décadas (Rawwas et al., 2013). Este crescente interesse e visibilidade da ética podem ser atribuídos, em parte, a uma sequência de escândalos, ocorridos desde a década de 1980. Constata-se, desde então, um recurso incessante à ética. Esta tendência, não depende do acaso, explica-se, antes, pelas necessidades do momento (Mercier, 2003). A ética é vista como uma forma de auxiliar indivíduos e organizações nas suas escolhas de modo a que assegurem ganhos de sustentabilidade (Gambim, et al., 2016)

A reconhecida falta de ética nos negócios, os elevados custos da não observância ética por parte das organizações, a consolidação das democracias, e o desenvolvimento tecnológico, que facilitou o acesso e a livre circulação de informação foram fatores determinantes para o aumento da visibilidade das problemáticas éticas que a gestão de negócios encerra.

A empresa é uma realidade humana complexa, com uma grande influência na economia e na sociedade. O trabalho é uma atividade humana e o atual ambiente em que a empresa se insere é fortemente concorrencial, mutante, exige novas formas de gestão, baseadas principalmente em valores que lhe confiram sustentabilidade e a capacidade de aproveitar as valências específicas da ética e da inovação. Em face a estas exigências, novos conceitos, estudos e formas de organização, surgem, para responder, eficientemente, aos atuais desafios (Boatricht, 2007). Neste sentido a ética pode funcionar como um agente motivador, que revigora, e ativa a democracia da sociedade e fornece também alegria, bem-estar, somando benefícios à atividade empresarial (Aguilar, 1996). São vários os autores que corroboram esta ideia, Blanchard (1989), Kenneth (1989), Aguilar (1996), Ferrell (2006), Rego et al., (2006), Skarzynski (2008), Almeida (2010).

Hoje, a gestão das organizações, ganha contornos cada vez mais sistémicos, exigindo, diferenciação, adaptabilidade, criatividade e multiplicidade de habilidades para garantir a sua sobrevivência. Neste contexto, são também vários os autores, Druker (1989), Carneiro (2001), Silva (2003), Schwartz (2005), Gebler (2007), Gupta (2008), Matin (2008), 
Isaksson et al., (2010) que afirmam: só as organizações que criem apetências sólidas e sistémicas permanentes de inovação sobreviverão aos tempos de mudança. Perante este desafio, as empresas necessitam de utilizar todos os recursos disponíveis e, neste campo a ética e a inovação poderão desempenhar um importante papel no sentido da convergência para a competitividade e sustentabilidade organizacional. Cada vez mais a inovação é vista como a grande força de transformação aplicada por organizações e sociedades é o objeto e o instrumento através do qual se explora a mudança (Silva, 2003). Hoje, as organizações, por pressão da competição, estão a procurar novas formas de desenvolver e aplicar inovação nos seus processos, produtos e serviços (Gupta, 2008). Ao ser humano cabem tarefas em que é insubstituível; ser criativo, ter ideias que levem à inovação de produtos e serviços (Boatricht, 2007).

Quando se estuda mais profundamente esta temática, constata-se que a ética, inovação e sustentabilidade organizacional são um conceito em construção, quer a nível mundial e principalmente em Portugal. O próprio tema, parece estar, ou melhor, está em processo de definição. Diante da ambiguidade e da crescente complexidade das práticas empresariais contemporâneas, fruto das novas exigências de competitividade, eficiência e inovação, a reflexão sobre a ética e inovação, serve de base para que se tenha coesão organizacional. Neste sentido, investigar a relação entre a ética e a inovação e analisar qual o contributo na sustentabilidade organizacional, parece fazer todo o sentido. Por outro lado, a reconhecida falta de compreensão teórica do tema, e a tentativa de exercer sobre ele alguma clarificação, estiveram na origem da problemática desta investigação.

Este estudo enquadra-se no tema geral da ética empresarial, entendida como um compromisso empresarial que permite potenciar a inovação, crescimento económico, social, e a sustentabilidade das organizações a médio e longo prazo. Tem como objetivo, construir um modelo conceptual, a partir da revisão da literatura, que permita compreender o contributo da ética na promoção de comportamentos e relacionamentos internos que promovam a predisposição da inovação empresarial e para a sustentabilidade organizacional.

\section{REVISÃO DA LITERATURA}

\subsection{A ética}

Etimologicamente, a ética provem da palavra grega ethos, que significa costume. Mas os costumes são determinados por valores morais e pelas leis vigentes, as quais condicionam a conduta humana numa determinada época (Rocha, 2010). Os valores são os princípios ou padrões de comportamento 
de uma pessoa. Mas um valor torna-se realidade se e só se a sociedade como um todo o reconhecem no seu valor total (Schwartz, 2005). Por outro lado, em toda a ação humana há critérios motivacionais importantes que melhoram a ação, que são os critérios internos da consciência humana valores, princípios ou padrões de comportamento de uma pessoa (Hoyos, A.T. and Braun, 2010).

Embora a teoria ética seja, desde a sua origem, por natureza e condição, uma disciplina filosófica, a ética nos negócios recebe influência de outros campos, como a epistemologia, antropologia filosófica ou ontologia (Stahl et al., 2014). Para Alonso, López e Castrucci (2010), a filosofia e, por conseguinte, a ética busca discernir a boa e a má conduta e a relação entre conduta adequada e felicidade. Os seus fundamentos contribuem amplamente para o avanço do conhecimento em disciplinas, como a sociologia, psicologia e, mais recentemente, a administração de empresas. Segundo Boatricht (2007), a ética é o conjunto de regras, princípios ou maneiras de pensar que guiam, a autoridade de guiar, as ações de um grupo em particular a moralidade, ou o estudo sistemático da argumentação sobre como devemos agir. Segundo Kenneth (1989), a ética, é a ciência do dever, a qual rege a conduta humana. Para Isaksson et al., (2010) a organização ética pode ser descrita como tratando os stakeholders com honestidade, justiça, e respeito com o foco no longo prazo procurando satisfazer os interesses de todos. Isto implica dizer que a ética pode ser conceituada como o estudo dos juízos de apreciação que se referem à conduta humana suscetível de qualificação do ponto de vista do bem e do mal, seja relativamente a determinada sociedade, seja de modo absoluto.

A revisão da literatura permite-nos salientar as principais teorias éticas com maior impacto no mundo empresarial. O primeiro grande estudo sobre ética foi realizado por Aristóteles, na Grécia antiga, há cerca de 2.350 anos atrás. Para Aristóteles, a ética é a ciência prática do bem; e bem é "o que todos desejam". Aristóteles, ligou o estudo da ética e do bem à política e demonstrou que muito mais importante que o bem-estar do indivíduo é o bem-estar do coletivo (Boatricht, 2007). A ciência política não somente deve conhecer o bem, mas deve realiza-lo. Segundo Aristóteles, o bem próprio do homem é a inteligência e, portanto, o homem tem de viver segundo a razão (Moreira, 1996). Seguindo-se a razão, chega-se às virtudes (Crockett, 2005).

Para Descartes, a ética simboliza toda a fé que a Idade Moderna depositava na razão humana. Só ela permitia construir um conhecimento absoluto. Em termos morais reconheceu que seria impossível estabelecer princípios seguros para a ação humana. O seu princípio ético consistia em seguir as normas e os costumes morais, que a maioria seguia, evitando desse modo ruturas ou conflitos (Rocha, 2010). 
Hume, veio realizar uma "revolução copernicana" na moral. Abandonava a perspetiva do "eu penso" de Descartes e passava ao "nós operamos", explicando o comportamento humano reconstruindo a sua génese, fazendo a anatomia da "natureza humana" através de uma ciência moral. O seu objetivo é construir uma ética empírica baseada em experimentação e observação, sem usar a metafísica (Neves, 2008).

A teoria de Kant é referida como a ética de responsabilidade e do dever que invoca a obrigação de justificar todo o ato ou decisão em função de normas morais e de valores (Kenneth, 1989). A ética de Kant é então a ética do dever em vez da ética da consequência. Para Rego et al., (2006), a ética Kantiana representa o respeito pela dignidade humana, pois trata os seres humanos dotados de direito a serem tratados com dignidade e respeito. Este respeito pelo ser humano é frequentemente tomado como imperativo e não operacional ou discricional.

A teoria utilitarista de Jeremy Bentham assenta o valor de uma ação não sobre princípios à priori mas sobre o princípio da utilidade (Rocha, 2010). É uma teoria ética porque diz respeito a se as ações humanas são certas ou erradas (Neves, 2008). A "ética utilitarista" defende que tudo o que contribua para o progresso social é bom. A ideia intuitiva por detrás do utilitarismo é a de que nós deveríamos agir para conseguir as melhores consequências dos atos praticados (Rocha, 2010). Neste ponto de vista, o que interessa, é saber se as consequências das decisões éticas tomadas são ou não, benéficas para a maioria das partes envolvidas, se são geradoras de bem-estar e de valor para o maior número de pessoas e organizações. Esta teoria define o bem-estar coletivo como a soma do bem-estar dos indivíduos que compõem a referida coletividade. O objetivo é a maior felicidade para o maior número possível de pessoas, (Almeida, 2010). Para, Rego et al., (2006), os utilitaristas acreditam que a função da moralidade é promover o bem-estar humano minorando os danos e aumentando os benefícios. No domínio dos negócios, a tradução desta lógica reside na maximização da eficiência, uma via para obter a máxima produção com a menor quantidade de recursos económicos, e um meio de obter mais elevados lucros com mais baixos preços.

A estas teorias seguiram-se as correntes filosóficas de Hegel, Marx, Rawls e Habermas, que marcaram uma corrente de pensamento distintas das teorias anteriores, pois concebem o mundo a partir do coletivo e não do individual (Serafim, 2004). Destacamos a "Teoria da justiça de Rawls, que articula de uma maneira coerente a adesão simultânea aos ideais de liberdade, justiça social, pluralidade ideológica e de igualdade, e a Teoria da Ação Comunicativa de Habermas, que valorizou a opinião pública e o espaço público crítico, a moralidade e a crítica reflexiva (Bannwart, 2011). A sua teoria apresenta uma perspetiva mais meta-ética da ética da 
comunicação (Arnsperger e Parijs, 2004), nesta teoria a atenção está voltada para a justificação da ética discursiva a partir do princípio da universalidade, o que o inclui na tradição kantiana, entre os defensores de uma moral racional e universal (Bannwart, 2011).

As exigências éticas, hoje, não se esgotam no que está estabelecido de forma mais ou menos extensa numa lista de direitos e deveres. O principal contributo da ética para a vida económica e empresarial não é tanto evitar o mal, mas ajudar a fazer mais e melhor (Aguilar, 1996). Um mais e melhor que não se deve limitar aos objetivos intrínsecos da organização, já que há que ter bem em conta outros interesses que obrigam a ver a empresa à luz da sua integração num ambiente mais vasto, global e com mais transparência. Arruda et al., (2001) vão mais longe ao afirmar que a ética é condição necessária para a sobrevivência humana e da sociedade.

Durante vários séculos, as relações entre a economia e a ética foram inexistentes (Ferrell, 2006). A partir da década de 70 do século passado, primeiro nos EUA e depois na Europa e no resto do mundo, começou a evidenciar-se a compatibilidade entre atuações eticamente corretas e negócios prósperos (Boatricht, 2007). Aguilar (1996) considera, mesmo, que uma atuação ética na condução dos negócios pode ser fonte de lucros. Blanchard e Peale (1989), Rego et al., (2006), Gebler (2007) também argumentam que, combinada a uma sólida estratégia de negócios, a ética na empresa cria um clima organizacional capaz de motivar iniciativas inovadoras e ousadas que são essenciais para obter e manter a excelência nos negócios. Segundo Aguilar (1996), a implementação de uma ética empresarial, proporciona aos funcionários e outros interessados a oportunidade de trabalhar numa atmosfera de confiança e respeito mútuo, podendo fornecer a líderes empresariais condições favoráveis à promoção da inovação e aceitação de riscos. Segundo este autor, é inatacável, que o compromisso com a conduta ética gera relações empresariais produtivas e tira das pessoas o que elas têm de melhor. Da mesma maneira que a conduta antiética tem o potencial de arruinar a empresa, o comportamento ético tem o de contribuir, de forma importante para a obtenção da excelência empresarial (Aguilar, 1996).

Muitos lideres ainda falam da cultura ética como um extra. Agindo com integridade, apenas para suavizar valores agressivos (Gebler, 2007). Suchanek (2008) enfatiza que a ética não compensa sempre mas que o alinhamento do sucesso corporativo e responsável é um dos desafios centrais de uma "boa gestão". A diversidade de papéis torna a gestão e administração de empresas uma atividade com profundas implicações éticas, com impactos estruturantes no bem-estar individual e coletivo (Almeida, 2007). Nesse sentido Gebler (2007) propõe um padrão ético que seja compatível com diferentes sistemas de valores globais (vindos das 
diversas culturas e religiões) e também com modernos conceitos de gestão, como o Corporate Social Responsability (Responsabilidade Social Corporativa) (CSR). Esta regra de ouro pede o investimento nas condições que fomentam cooperação social e benefício mútuo. Tal padrão ético altamente compatível encaixa particularmente bem com a questão da sustentabilidade em cadeias de distribuição globalmente espalhadas, onde diferentes culturas, sistemas sociais e culturas de gestão colidem (Isaksson et al., 2010). Segundo Martínez (2015) a ética é uma filosofia de vida, é a arte de uma boa vida, de qualidade de vida e de sentido de vida.

A ética é, antes de mais, algo positivo para o indivíduo, organização e para a sociedade. Pois visa o bem, individual e coletivo, o respeito pela dignidade humana, a maximização da eficiência e o sucesso individual, organizacional e social.

\subsection{A inovação}

A inovação fez sempre parte da humanidade. Desde a descoberta do fogo, que o ser humano tem vindo a inovar. A inovação é, provavelmente, o mais antigo processo que se conhece, é uma extensão da criatividade dos seres humanos. Desde sempre que utilizamos as nossas habilidades inatas para criar muitas coisas novas e para ajudar a espécie humana (Gupta, 2008). Segundo Gupta, as inovações têm por base o conhecimento do passado, a experimentação contínua e a dimensão do conhecimento passado e da experimentação. Para Drucker (1999) a inovação é a ferramenta específica do empreendedor, o meio com o qual ele explora a mudança como uma oportunidade para um negócio ou serviço diferente, sucessível de ser entendida e praticada.

Matzler et al., (2008); Isaksson et al., (2010); Morales et al., (2012) argumentam que a inovação permite às empresas sustentar as suas vantagens competitivas é essencial à sua sobrevivência e permite melhorar o desempenho organizacional. Hoje, a inovação surge como uma variável determinante para o sucesso organizacional (Gambim et. al., 2016). Cada vez mais a inovação é vista como a grande força de transformação aplicada por organizações e sociedades (Gupta, 2008). Sabe-se que o crescimento económico está, em larga medida, associado à capacidade inovadora que resulta não só da inovação tecnológica, derivada da investigação e da sua aplicação, mas também da inovação organizacional (Jiménez e Valle, 2011). Logo, um dos maiores desafios das organizações e dos agentes que com elas interagem consiste no apoio e na implementação de posturas e práticas inovadoras no seu quotidiano.

Neste sentido, Baucus et al., (2008) sugerem que as organizações devem criar ambientes que permitam e incentivem os funcionários a envolver-se em criatividade. Mas, muitas abordagens para aumentar a 
criatividade levantam questões éticas. Nesse sentido, as Inovações não só podem ser consideradas como uma resposta às ameaças, mas também como uma maneira de abraçar novas oportunidades (Matzler et al., 2008).

Hoje em dia falar de inovação não chega, é necessário passar à ação. Como refere Conceição (2002) "talvez seja agora, mais do que nunca, que importa avançar decisivamente com ações concretas. Para tal, importa recolher tanta informação quanto possível sobre o que se sabe relativamente ao que determina e condiciona o processo de inovação". Tendo em vista obter não apenas resultados, mas sobretudo criar valor e vantagens competitivas (Sarkar, 2009), e por consequência sustentabilidade organizacional. Para Sarkar, (2009) a inovação pode ser enfatizada segundo um conjunto de vários elementos e variáveis: ideia, oportunidades, alternativas representadas na figura 1.

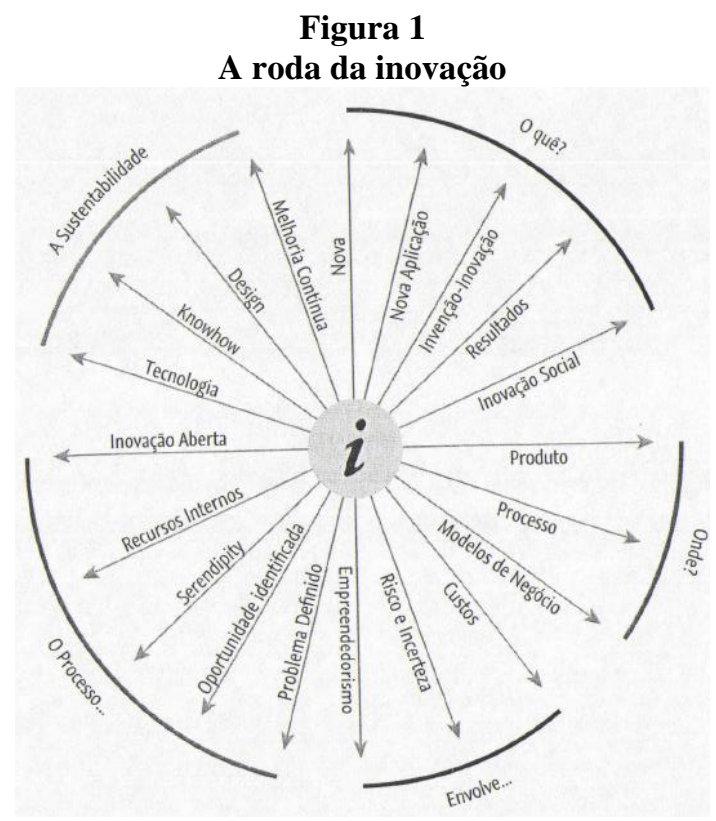

Fonte: Sarkar (2009)

A figura 1 permite; uma visão global das diferentes vertentes da inovação; sintetizar vários conceitos de inovação e uma análise holística. Pode ser analisada em quatro vertentes: compreender o que é a inovação, que tipos de inovação ou onde inovar, qual o processo geral de inovação e, por último, de onde surge a sustentabilidade de inovação. 
Quando se fala de inovação, a maioria das pessoas, parte imediatamente do princípio de que se está a referir ao desenvolvimento de um novo produto ou tecnologia de ponta. No entanto algumas das inovações mais bem-sucedidas do nosso tempo têm sido as inovações no modelo de negócios, que rompem com as normas da empresa (Gupta, 2008). Embora a inovação possa estar intimamente ligada a aplicações de carácter tecnológico, não tem que ser necessariamente assim. A inovação pode ter um carácter muito mais amplo, não envolvendo diretamente a tecnologia mas incluindo sim, alguma mudança social, como é o caso do modelo de microcrédito iniciado por Muhammad Yunus (Prémio Nobel da Paz), que tem sido um instrumento decisivo contra a pobreza (Sarkar, 2009). De igual modo, a inovação que envolve alterações nos modelos ou formas de negócio, a inovação organizacional, ou a inovação dos sistemas de distribuição, não têm necessariamente de envolver um avanço tecnológico (Martin, 2008). Segundo Gupta, (2008) as empresas tendem a enfrentar seis barreiras internas à inovação; a cultura, a estratégia, os processos, os métodos, as ferramentas e o tempo. Os fundamentos, da ética empresarial tem o potencial para eliminar, ou pelo menos suavizar estas barreiras, promovendo condições para o desenvolvimento da inovação.

No atual contexto, as empresas têm que se reinventar continuamente o que são e o que fazem, quer seja por pequenas, quer grandes mudanças. Devem desenvolver novos produtos, serviços e métodos organizacionais para aumentarem os seus resultados (Sarkar, 2009). Várias abordagens teóricas, desenvolvidas nos últimos anos, sustentam que a inovação resulta de um processo não linear, evolucionário, complexo e interativo entre a empresa e o seu meio envolvente (Silva et al., 2005). Campell e Kitson (1996), afirmam que o sucesso das organizações situa-se mais nas suas capacidades intelectuais e holísticas do que nos ativos físicos, mais no campo de geração de ideias do que na geração de ativos tangíveis, onde a capacidade de gerir o potencial humano se transforma numa habilidade executiva essencial. Ao nível macroeconómico, a inovação está intimamente ligada com o crescimento económico e com o bem-estar dos povos (Sarkar, 2009). Neste campo, a ética poderá ter um importante papel ao promover ambientes de bem-estar, transparência, confiança e estimular estas capacidades.

A relevância da inovação para a atividade empresarial tem mesmo levado alguns autores a considerarem-na uma condição necessária para a sobrevivência e já não apenas uma opção estratégica (Cunha, 2007). Neste sentido a adoção de um modelo de ética empresarial, fundamentado na legalidade; humanismo; transparência; valores; responsabilidade social e cultura organizacional, poderá servir de alavanca para a promoção de condições promotoras da inovação empresarial e em conjunto, ética e 
inovação poderão constituir-se como processos fundamentais para a sustentabilidade da empresa. Hoje é consensual que a adoção dos valores e princípios éticos traz eficiência e contribui para o bom desempenho organizacional (Aguilar, 1996).

\subsection{Relação entre ética, inovação e sustentabilidade organizacional}

A inovação é uma grande força de transformação aplicada por organizações e sociedade. E está a ser considerada como a mais estrita função empresarial (Cunha 2007). O reconhecido aumento de competitividade, requer, agilidade, flexibilidade e capacidade de adaptação e inovação, por parte das organizações para poderem sobreviver (Rego et al., 2006). Porter (1990) afirma que as empresas geram e conservam as suas vantagens competitivas primordialmente através da inovação.

Como em todas as decisões de negócios, as inovações têm implicações éticas que devem ser abordadas (Martin, 2008), a regra-chave da inovação, deve orientar os gestores a tomarem decisões importantes sobre as suas inovações e ajudar a sua empresa a criar inovações que sejam boas para ambas as partes, organização e comunidade, este é o princípio do utilitarismo. Martin (2008) sustenta que as inovações mudam a vida das pessoas com impactos de curto e longo prazo e só as inovações mutuamente benéficas são sustentáveis. Neste sentido, só as inovações desenvolvidas segundo valores e princípios éticos sobreviverão.

Segundo Gebler (2007), há uma forte relação entre empresas inovadoras e empresas éticas. Empresas que procuram um, muito provavelmente procurarão outro. Porque os valores críticos de respeito, transparência e confiança são protegidos encorajados e recompensados. Estas organizações são flexíveis e dispostas a tomar riscos, elas consideram as ideias e opiniões dos empregados e procuram criar um clima onde todos sintam que a sua voz é ouvida. Para poder fazer florescer valores como respeito e confiança os líderes devem prestar contas, a eles próprios e aos outros (Gebler, 2007). Segundo este autor, os comportamentos específicos que ligam a ética a inovação e produtividade, devem ser encorajados, pois levam à confiança dentro da organização. Confiança que gera bem-estar e que por sua vez, promove a predisposição para a inovação. Contudo até que os líderes percebam que a conduta ética é essencial para alcançar os objetivos de negócio, a ética estará sempre na margem da tomada de decisão em negócios.

A inovação e produtividade só podem ser alcançadas quando as pessoas criativas se sentem seguras num ambiente de trabalho ético onde as suas ideias são ouvidas e respeitadas. Seja encorajando um novo design de produto ou novos processos para fazer o workflow mais eficiente. As 
pessoas criativas precisam de sentir que as suas contribuições valem a pena e que são valorizadas por isso (Gebler, 2007).

Para a organização ser sustentável necessita de ir ao encontro dos requisitos dos stakeholders no que diz respeito ao comportamento ético. Mas para lá da questão de como se comportar de um modo saudavelmente ético de acordo com os requisitos dos stakeholders, a ética de negócio também procura dar resposta em como a moralidade e o interesse pessoal podem ser utilizados para alcançar benefício mútuo (Isaksson et al., 2010). As empresas devem promover uma abordagem mais sistémica da inovação, no sentido de tornar a inovação uma capacidade empresarial sustentável (Gupta, 2008).

A inovação, para que funcione realmente e seja sustentável, deve tornar-se uma capacidade sistémica e difundida de forma abrangente, deve estar impregnada na estrutura quotidiana da empresa, tal como qualquer outra capacidade organizacional, como a qualidade, ou o serviço de atendimento ao cliente. A inovação deve tornar-se um modo de vida da organização (Gupta, 2008). Infelizmente, a maior parte das empresas nunca chega a este ponto de viragem e nunca conseguem tornar a inovação algo mais do que uma coisa que está «aparafusada» em vez de embutida. Em vez de minimizar a interação entre os esforços de inovação e de eficiência da empresa, deve conceber os seus sistemas organizacionais de modo a que os dois ideais estejam em permanente contacto (Gupta, 2008). Segundo o autor, muitos começam a reconhecer que a inovação deve ser introduzida em toda a organização, deve ser algo que exige outros valores, mentalidades, competências, comportamentos, processos, modelos de gestão, indicadores de desempenho, prémios, estruturas organizacionais, soluções de TI em toda a empresa.

Este contexto, das novas exigências económicas, organizacionais e sociais, constitui, uma oportunidade das empresas recriarem as suas estruturas, processos, mentalidades, códigos, saberes, e implementarem a ética empresarial, com vista à excelência e sustentabilidade dos negócios. Sabendo que o bem-estar a longo prazo depende das capacidades de nos recriarmos a nós próprios e às organizações, torna-se essencial à sobrevivência a inovação sistemática em todos os níveis da empresa.

No futuro, a investigação relacionada com a ética beneficiará muito se tomar em consideração a mudança de referência do discurso para a ética aplicada e se relacionar ética com outras preocupações mais práticas (Stahl et al., 2014). Os estudos realizados na área das ciências económicas e empresariais tentam encontrar um elo de ligação entre a inovação e comportamento ético (Pollifrone, 2010). Também Argandoña (2004) considera que a gestão ética deve ser integrada com outras práticas de gestão. Tendo em conta que a ética pode ser aplicada a quase todos os 
campos da atividade humana (Alonso, 2013), a sua aplicação no desenvolvimento da inovação trará grandes benefícios, pois a inovação é considerada um dos processos imprescindível à sustentabilidade das empresas.

Amartya Sen propôs um modelo institucional, segundo o qual o êxito económico depende da tecnologia, da iniciativa privada, da liderança, das políticas comerciais, da eficácia dos sistemas financeiros, das políticas públicas e, muito especialmente, de uma ética que garanta o cumprimento quotidiano dos convénios com os trabalhadores, os acionistas, os diretivos, os clientes e as instituições públicas infundindo confiança, pois há que satisfazer as expectativas legítimas de todos (Sen, 1999).

\section{PROPOSTA DE MODELO CONCEPTUAL E HIPÓTESES A TRATAR}

De acordo com a revisão da literatura exposta e tendo por base as sistematizações feitas ao longo do estudo, propõem-se o modelo conceptual, (figura 2), que foi desenvolvido de modo a sintetizar a relação entre a ética e a inovação, a partir da qual se exploram ideias, organizam fenómenos, identificam variáveis e dimensões pertinentes, possibilitando a análise da inter-relação existente entre elas. Permite também definir hipóteses, a serem testadas.

Figura 2

Modelo Conceptual

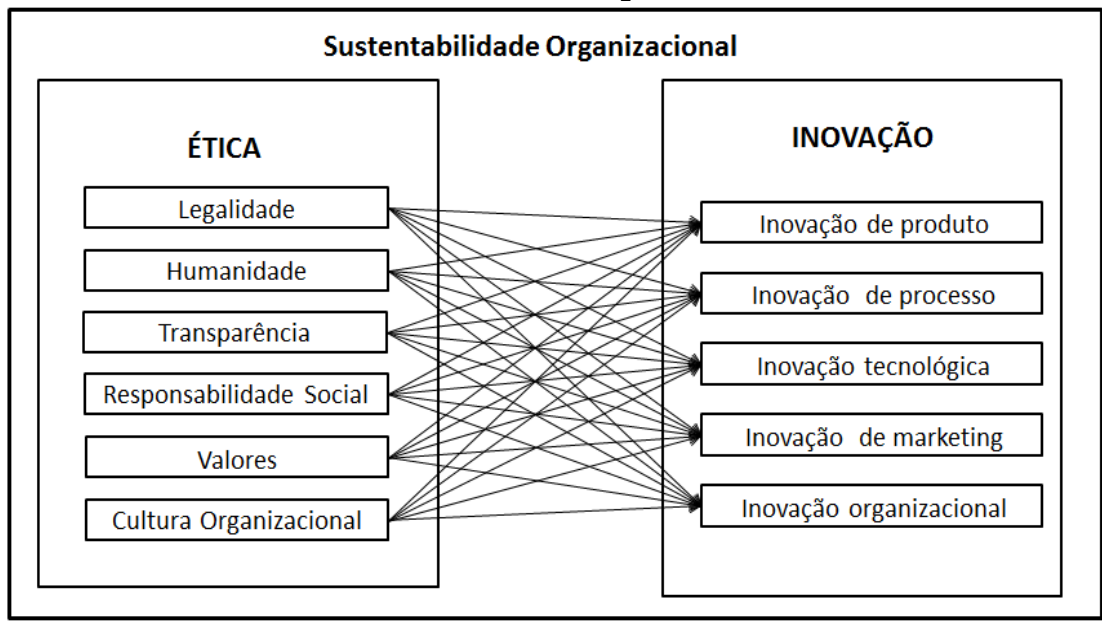

Fonte: Elaboração própria 
Do modelo teórico proposto, das relações conceptuais que dele derivam e, da revisão da literatura, resultam um conjunto de hipóteses teóricas passíveis de serem testadas empiricamente.

Hipótese I - A gestão ética promove a inovação e a sustentabilidade organizacional.

Hipótese II - Os valores promovidos pela gestão ética têm um impacto positivo na propensão para a inovação do produto, processo, organização e promovem a capacidade inovadora.

Hipótese III - A capacidade inovadora do indivíduo, é influenciada pelo ambiente de legalidade e humanidade, gerados pela gestão ética.

Hipótese VI - A transparência, e a cultura organizacional neutralizam as barreiras internas à inovação.

As hipóteses têm o objetivo de orientar a investigação da relação entre a ética e a inovação e o seu contributo para a sustentabilidade empresarial, permitindo sustentar as conclusões.

\section{CONSIDERAÇÕES FINAIS}

Gerir uma empresa segundos os princípios éticos, pela sua visibilidade e popularidade, é hoje, o desejo de muitos (Almeida, 2010). De facto, implementar uma gestão ética nas empresas, é sem dúvida a grande tendência e desejo de gestores, diretores e empresários, mas a falta de conhecimento e compreensão da sua natureza e espaço, bem como dos seus princípios e benefícios, dificultam a tomada desta decisão. Por outro lado, a aplicabilidade da ética empresarial é ainda ineficiente, sendo os seus resultados pouco visíveis e os retornos de difícil perceção e quantificação. Mas, se aos benefícios da ética, juntarmos os benefícios da inovação poderão estar reunidas forças incrementais para a sustentabilidade organizacional.

A ética empresarial é, antes de mais, uma ciência que promove a legalidade, humanidade, a transparência, a responsabilidade social, os valores e uma cultura organizacional, capaz de criar condições promotoras das melhores decisões, a nível individual e organizacional e, nesse sentido, promover a inovação de produtos, processos, tecnologias e marketing organizacional.

No atual contexto dos mercados, as organizações vêem-se obrigadas a repensar os seus modelos de gestão e a exigida adaptação passará pela adoção da ética empresarial e pela inovação. Nesse sentido, o estudo sistemático da temática traz valor, para o indivíduo e para a organização, possibilitando uma melhor compreensão do tema, o desenvolvimento científico da ética e inovação e a promoção da implementação da Ética Empresarial. A investigação efetuada permite argumentar que o estudo da relação entre ética e inovação pode ser uma utopia possível, cada vez mais 
pertinente, quer pela sua influência na economia moderna, quer pela influência na competitividade e sustentabilidade organizacional.

$\mathrm{O}$ estudo apresenta como principal limitação, o fato de não ter sido testado o modelo teórico e as hipóteses formuladas, pelo que as conclusões retiradas podem ser contestadas, nesse sentido propõe-se que futuras investigações sobre o tema testem o modelo e as hipóteses de forma a sustentar e generalizar as conclusões.

\section{BIBLIOGRAFIA}

Aguilar, F. J. (1996) A Ética nas Empresas, Managing Corporate Ethics: Learning from América's Ethical Companies How to Supercharge Business Performance, tradução autorizada da $1^{a}$ edição publicada em 1994 por Oxford University Press, Nova York, Jorge Zahar Editor, Rio de Janeiro

Alonso, Andoni (2013). "Ética en la innovación y el movimiento Open* Ethics on Innovation and the Open Movement, Revista de Filosofía Moral y Política, N. ${ }^{\circ}$ 48, enero-junio, 2013, 95-110, ISSN: 1130-2097 doi: 10.3989/isegoria.2013.048.05

Alonso, F. R.; López, F. G.; Castrucci, P. de L. (2010) Curso de ética em Administração. São Paulo: Atlas.

Almeida, F. (2010) Ética, Valores Humanos e Responsabilidade Social das Empresas, Principia Editora, Braga

Amaral, P. C., Pedro, J. M. (2004) O Capital conhecimento - Modelos de avaliação de activos intangíveis, Universidade Católica Editora, Lisboa Argandoña, A. (2004). "On Ethical, Social and Environmental Management Systems", Journal of Business Ethics, Vol.51, pp.41-52, Kluwer Academic Publishers. Printed in the Netherlands

Arruda, M. et al (2001) Fundamentos de Ética Empresarial e Económica, Editora Atlas, São Paulo

Bannwart, C. J. (2011). Moral pós-convencional e os impasses do desenvolvimento sustentável, in Costa et al., (2011) Responsabilidade Social - Uma Visão Ibero-Americana, (Org.), Almedina, Coimbra

Baucus, Melissa S.; Norton, William I.;Baucus, David A.;Human, Sherrie E. (2008). "Fostering Creativity and Innovation without Encouraging Unethical Behavior", Journal of Business Ethics, Vol.81, pp.97-115 _ Springer 2007 DOI 10.1007/s10551-007-9483-4

Blanchard, K. and Peale, N. V. (1989) The Power of Ethical Management, Difusão Cultural, Lisboa

Boatricht, J. R. (2007) Ethics and the conduct of Business, Prentice Hall, London 
Brady, N. and Hart, D. (2007) An Exploration into the Developmental Psychology of Ethical Theory with Implication for Business Practice and Pedagogy, Journal of Business Ethics (2007) 76:397 - 412

Campell, R. e Kitson, A. (1996) The Ethical Organisation - Ethical Theory and Corporate Behavior, Macmillan Business, London

Carné, D. M. (1999) Consideraciones éticas sobre la iniciativa empreendedora Y la empresa familiar, Ediciones Universidade de Navarra

Carneiro, R. (2001) Inovação estratégica e competitividade, Texto Editora, Lisboa

Carroll, A. and Buchholtz (2006) Bussiness Society, Ethics and Stakeholder Management, International Student Edition, EUA

Chesbrough, H. (2003) Open Innovation: The New Inperative For Creating And Profiting From Technology, Harvard Business School Press.

Cifuentes, C.L. (1997) Dilemas Éticos de la empresa contemporânea, México

Conceição, P. e Ávila, P. (2001) Inovação em Portugal, Celta Editores

Cortina, A. (2003) Ética de la empresa - Claves para uma nueva cultura empresarial, Editorial Trotta, sexta Edicion, Madrid

Crockett, C. (2005) The Cultural Paradigm of Virtue, Journal of Business Ethics (2005) 62: 191-208

Cunha, Miguel Pina; Rego, Arménio; Cunha, Rita Campos; Cardoso, Carla Cabral (2007). Manual de Comportamento Organizacional e Gestão, Editora RH, Lda, 6a Edição, ISBN: 978-972-8871-16-1

Drucker, Peter (1985) Innovation \& Entrepreneursship: Practice and Principles, Boston, Butterworth Heinemann

Drucker Peter (1989) Inovação e Gestão. Uma nova concepção de estratégia de empresas. Editorial Presença.

Drucker, Peter (1992) "Reflections of a Social Ecologist, "Society, May/June 1992

Drucker, Peter (1999) Desafios Gerências para o século XXI, São Paulo, Editora Pioneira

Drucker, Peter (2000) The Ecological Vision. Reflections on the Americam Condition, New Brunswick, Transaction Publishers

Drummond, J. \& Bain, B. (1994) Managing Business Ethics, Oxfod, London

Europeun Commissin (2004) Innovation Management and the Knowldge Driven Economy Publication Office, Belgium

Fasterling, Bjorn (2009) The Managerial Law Firm and the Globalization of Legal Ethics, Journal of Business Ethics (2009) 88: 21-34 
Felgueira, T., Vital, F., Silva, M. J. (2010) Actividades de I\&D Principais Determinantes da Capacidade Inovadora de Marketing "proceeding of IASK Conference GM2010

Ferrell, O. C., John Fraedrich, Linda Ferrell (2006) Business Ethical: Ethical Decision Making and Cases, Houghton Mifflin Company, 6 th edition

Fourez, G. (1995) Como articular ciência e ética? In: A construção das ciências: introdução à filosofia e à ética das ciências. São Paulo: UNESP, 1995. p. 297-306.

Forster, N. (1994) The analusis of company documentation. In C. Cassel and G. Symon (eds). Qualitative methods in organizational research. London

Gambim, L. G., Neto, J.A., Targino, M.G. (1016) Ethics and Innovation in the Context of the Information Society, Rev. FSA, Teresina, v. 13, n. 3, art. 5, p. 94-110, mai./jun. 2016

Gebler, David (2007). The Link Between Ethics and Innovation, in http://corporate.smartpros.com/ethics/index.html (acedido 14-10-2013)

Germak, Andrew J. and Singh, Karun K.(2010), 'Social Entrepreneurship: Changing the Way Social Workers Do Business', Administration in Social Work, 34: 1, 79-95, http://dx.doi.org/10.1080/03643100903432974

Giovanola, B. (2009) Re-Thinking the Anthopological and Ethical Foundation of Economics and Business: Human Richness and Capabilities Enhancement, Journal of Business Ethics (2009) 88:431444

Grane, Andrew and Dirk Mattem (2006) Business Ethics - Managing Corporate Citizenship and sustainability in the Age of Globalizatin, Oxford University Press; 2ed edition

Gupta, Praveen (2008) Inovação empresarial no século XXI, Grupo Editorial Vida Económica, Porto

Kenneth, Andrews, (ed) (1989) Ethics in Pratice - Managing The Moral corporation, Harvard Bussiness Shool Pres, Boston

Hope, J e Hope, (1997), Competing in the Trird Wave, Boston, MA, Harvard Business

Ibrahim, N., Agelidis, J., Tomic, I. M. (2010) Managers`Attitudes Toward Codes of Ethics: Are There Grander Differences?, Journal of Business Ethics, (2010)Doi 10.1007/s 10551 -010-0428-y

Isakssun, K. and Massimo Pollifroni (2010), Empirical evidences of correlation between Innovation and ethical behavior in the EU Countries Area, Economia Aziendale Online 4(2010) -359 -371, www.ea2000.it 
Isaksson, R. Peter Johansson, Klaus Fischer, Detecting Supply Chain Innovation Potential for Sustainable Development, Journal of Business Ethics (2010) 97:425-442, Springer 2010

Jiménez, Daniel e Valle, Raquel Sanz (2011). "Innovation Organizational Learning and Performance", Journal of Business Research, Vol.64, pp. 408-417

Ladkin, D. (2006) When Deontology and Utilitarianism Aren't Enough: How Heidegger's Notion of "Dwelling" Might Help Organisational Leaders Resolve Ethical Issues, Journal of business Ethics (2006) 65: 87-98

Knights, D. and O`Leary, M. (2006) Leadership, Ethics and Responsibility to the Other, Journal of Business Ethics (2006) 67: 125-137

Lopez, J.A.P. (1998) Liderango Y ética em la direccion de empresas la nueva empresa del sglo XXI, Ediciones Deusto S. A. Bilbau

Madsen, Peter and Jay M. Shafritz (ed) (1990) Essentials of Business Ethics, Meridian Books, New York

Marcus Wagner (2010), Corporate Social Performance and Innovation with High Social Benefits: A Quantitative Analysis, Journal of Business Ethics (2010) 94:581-594, DOI 10.1007/s10551-009-0339-y

Marcier, S. (2003) A ética nas empresas, tradução de Esteves António Joaquim e Soares, Conceição, Edições Afrontamento, Lisboa

Martin, Kirsten E., Innovation Ethics and Business, Featuring a Thought Leader Commentary ${ }^{\text {tm }}$ WIth Anne M. Mulcahy, Chairman and Chief Executive Officer, Xerox Corporation, 2008, Business Roundtable Institute for Corporate Ethics, www.corporate-ethics.org

Martínez, P.C (2015) Ética e Sustentabilidade, rev.latinoam.bioet. / ISSN 1657-4702 /Volumen 15 / Número 1 / Edición 28 / Páginas 130-141 / 2015

Matzler, Kurt, Kepler, Johannes, Schwarz, Erich, Deutinger, Natasa, Harms, Rainer (2008). "The Relationship between Transformational Leadership, Product Innovation and Performance in SMEs", Journal of Small Business and Entrepreneurship, Vol. 21, No 2, pp. 139-152

Moreira, J. M. (1996) Ética, Economia e Política, Lello Editores, $2^{a}$ edição, Porto

Moreira, J. M. (1999) A Contas com a ética Empresarial, Principia, $1^{\mathrm{a}}$ edição, Março

Moreira, J. M. (2001) Ética Empresarial, "Introdução”, Vida Económica, Lisboa

Neves, J. C.(2008) Introdução à Ética Empresarial, Principia Editores, Cascais

Pollifroni, Massimo (2010). Empirical evidences of correlation between Innovation and ethical behavior in the EU Countries Area, Economia 
Aziendale Online 4(2010), pp -359 -371, disponível em www.ea2000.it (acedido em 06-05-2013)

Popper, K. (1996), A Lógica da Pesquisa Cientifica, Editora Cultrix, 15 Edição, São Paulo.

Quivy, R.; Campenhoudt, L. (1998): Manuel de Investigação em Ciências

Sociais, Gradiva Publicações, $2^{\text {a }}$ Edição, Lisboa.

Rawwas, Mohammed Y. A.; Arjoon, Surendra; Sidani, Yusuf (2013). An

Introduction of Epistemology to Business Ethics: A Study of Marketing

Middle-Managers", Journal of Business Ethics, (2013) 117:525-539

DOI 10.1007/s10551-012-1537-6

Regajo, P. (2005) Ética e direcção de empresas, Edições AESE, Lisboa

Rego, A. et al (2006) Gestão ética e Socialmente Responsável, Ed. RH

Editora, Lisboa

Rego, A. et al (2003) Comportamento organizacional e gestão, Editora RH, Lisboa

Rego, A et al (2003) A gestão Ética e Responsabilidade Social das

Empresas, Um estudo da Situação Portuguesa, Ed. Principia

Richard, T. DE G. (2006) Business Ethics, Sixth Edition Hall, EUA

Rocha, A.S. (2010) Ética, Deontologia e Responsabilidade Social, Grupo

Editorial Vida Económica, Maia

Rodriguez, M.V. (2005) Ética e Responsabilidade social da empresa, Elsevier Editora, S. Paulo

Sarkar, S. (2009) Empreendedorismo e Inovação, Escolar Editora, Lisboa

Schwartz, M. and Spong, H. (2005) Universal Moral Values for Corporate

Codes of Ethics, Journal of Business Ethics, (2005) 59:27-44

Schwartz, M. and Spong, H. (2009) Subjectivist Economics and Ethical Business, Journal of Business Ethics, (2009) 90: 123-136

Sequeira, C. F. P. (2001) Valores e Comportamentos Éticos na Competitividade das Empresas: o caso do Distrito da Guarda, Dissertação de Mestrado em Gestão, Universidade da Covilhã

Serafim, M., R. (2004). "O reconhecimento da condição ética dos cidadãos - um imperativo para o serviço social”, Revista Intervenção Social, Vol. 29, pp. 25-52, ISBN: 0874-1611

Silva, M.J. (2003) Capacidade Inovadora Empresarial: Estudos dos

Factores Impulsionadores e Limitadores nas Empresas Industriais Portuguesas, Tese de Doutoramento, Universidade da Beira Interior, Covilhã.

Singer, A. E. (2010) Integrating Ethics and Strategy: A Pragmatic Approach, Journal of Business Ethics (2010) 92:479-491

Skarzynski, P. and Gibson, R. (2008) Inovation to the Core - A Blueprint for Transforming the way Your Company Innovates, Harvard Business School Publishing Corporation, London. 
Sen, Amartya (1999). Sobre ética e economia, Companhia das letras, São Paulo

Siu, N.Y.M., Lam, K. C. J. (2009) A Comparative Study of Ethical Perception of Managers and Non -Managers, Journal of Business Ethics 88: 167-163

Spash, C.L., Ethics and Environmental Attitudes With Implications for Economic Valuation, Jornal of Environmental Manegement (1997) 50, 403-416, Department of LandEconomy, University of Cambridge.

Schrör, Hartmut (2008) Innovation as a Factor in Business Success, Manuscript completed on: 15.02.2008, Data extracted on: 23.10.2007, ISSN 1977-0316, Catalogue number: KS-SF-08-015-EN-N, (C) European Communities

http://www.slideshare.net/victori98pt/innovation-as-a-factor-inbusiness-success

Srour, R. H. (1998) Poder cultural e ético nas organizações, Elsevier editora, São Paulo

Stahl, B. Carsten; Eden, Grace; Jirotka, Marina; Coeckelbergh, Mark (2014). "From computer ethics to responsible research and innovation in ICT The transition of reference discourses informing ethics-related research in information systems", journal home page: www.elsevier.com/lo cate/im, INFMAN-2690; No. of Pages 9

Stieb, J. A, (2009) Assessing Freeman's Stakeholder Theory, Journal of business Ethics (2009) 87: 401-414

Tierney, E. P. (1998) Ética empresarial - Guia p7 directores, Griker \& Associados, Madrid

Trevino, Linda K. and Katherine A. N, (2007) Manajin Business Ethics Straight talk About How to do It Right, 4 th, John Wiley \& Sons Inc, New York

Velasques, M. G. (2002) Business Ethis - Concepts and cases, Fifth Edition, New Jersey

Wyburd, Giles (1998) Competitive and Ethical - How Bussiness canstriker a balance, Kogan, London

Yang, T., (2012) Hacia una ética ambiental global igualitaria. En A.M.J. ten Have Henk (Ed.) Ética ambiental y políticas internacionales (pp. 2550). París: Unesco. 